\title{
Electrochemical Sensing Ability of Ag/Mo-MCM-41
}

\author{
V. THATSHANAMOORTHY, R. SURESH, K. GIRIBABU, \\ R. MANIGANDAN and V. NARAYANAN*
}

\begin{abstract}
Department of Inorganic Chemistry, University of Madras, Guindy Maraimalai Campus, Chennai-600025, Tamilnadu, India

vnnara@yahoo.co.in
\end{abstract}

Received 19 January 2013 / Accepted 15 February 2013

\begin{abstract}
A new Ag/Mo-MCM-41 mesoporous electrocatalyst with different weight ratio of Si to Mo $(\mathrm{Si} / \mathrm{Mo}=25,50,100$ and 150) was prepared by direct hydrothermal (DHT) method. The synthesized Ag/Mo-MCM-41 was characterized by low angle x-ray diffraction (XRD) analysis, FESEM and FT-IR spectroscopy. The XRD of Ag/Mo-MCM-41 showed when incorporation of Mo into the MCM41 matrix, the mesoporous structure is distorted slightly and hence the intensities are found to decrease with increase in $\mathrm{Ag} / \mathrm{Mo}$ concentration. The morphological properties of the synthesized samples were studied by field emission scanning electron microscopy (FESEM) which shows the mesoporous electrocatalyst comprises of highly agglomerated particles. The FT-IR spectrum of the samples showed that the molybdenum was well incorporated within the MCM-41 frame work. The synthesized Ag/MoMCM-41 was used to modify glassy carbon electrode (GCE) and the modified electrode (Ag/MoMCM-41/GCE) was used to detect 4-chlorophenol (4-CP) in a $\mathrm{pH} 7.4$ phosphate buffer solutions (PBS) by cyclic voltammetry (CV). At the Ag/Mo-MCM-41/GCE, 4-CP oxidized at lower positive potential with larger current response than the bare GCE. The proposed sensor exhibits great potential in the field of electrochemical detection of organic pollutant.
\end{abstract}

Keywords: Mesoporous electrocatalyst, Electrochemical Sensing, Direct hydrothermal method

\section{Introduction}

MCM-41 was the first synthetic mesoporous material with regularly ordered pore arrangement and a very narrow pore distribution, which was disclosed by the Mobil scientists in $1992^{1}$. Since the discovery of MCM-41 by Mobil scientists, numerous studies have been reported concerning, preparation conditions, characterization and application of these materials as catalysts and catalyst supports in various reactions ${ }^{2}$. Pure siliceous hexagonal MCM-41 cannot be directly used as catalysts. It may be due to the limited thermal stability and negligible catalytic activity of this MCM-41, because of the neutral framework and the lack of sufficient acidity. Mesoporous metallosilicates, developed by isomorphous substitution of $\mathrm{Si}$ with different transition metal ions in a silicate structure, were used for catalysts in fine chemical industries to improve product yield ${ }^{3}$. In recent years, increasing attention has been directed towards the study of metal-containing mesoporous

\footnotetext{
$†$ Presented to the National Conference on Chemistry Solutions at SRM University, India
} 
molecular sieves. These mesoporous materials with large pores (20-100 $⿱$ ) are suitable for the transformation of bulky organic compounds ${ }^{4}$. Many researchers have reported the oxidation properties of metal ions such as $\mathrm{Ti}^{5}, \mathrm{~V}^{6}, \mathrm{Cr}^{7}, \mathrm{Mn}^{8}$ and $\mathrm{Mo}^{9}$ incorporated into the MCM-41 framework. With respect to redox catalysis, molybdenum is one of the important elements to be incorporated. The nature of supported Mo species depends on the acid-base properties of the support, the preparation conditions, and the Mo loading. The Mo surface species are stabilized in various oxidation states $(\mathrm{Mo}(\mathrm{I}), \mathrm{Mo}(\mathrm{II}), \mathrm{Mo}(\mathrm{III}), \mathrm{Mo}(\mathrm{IV}), \mathrm{Mo}(\mathrm{V})$ and $\mathrm{Mo}(\mathrm{VI})$ the presence of which depends on the factors mentioned above. In addition, the chemical composition of $\mathrm{MoO}_{3}$ clusters formed on the surface of amorphous or crystalline supports (e.g., oxygen-to- molybdenum ratio) is strongly influenced by the reaction conditions, such as the partial pressures of hydrogen, oxygen, and/or water. Upon heating in air, for example, water molecules are removed, while Mo(IV) ions (if present) are oxidized to Mo(VI). Surface hydroxyl groups anchor the resultant molybdenum oxide species. Depending on the reaction conditions, formation of anchored mono- or poly molybdates is possible ${ }^{10}$. In addition to molybdates, $\mathrm{Mo}(\mathrm{V})$ sites and molybdenum oxide clusters can also be formed on the surface of the calcined materials. Over the past decade, MCM-41 materials have been utilized either as a support or, after incorporation of metal ions such as molybdenum, as catalysts ${ }^{11}$. It was previously reported that molybdenum doped MCM-41 mesoporous siliceous materials, in which the molybdenum content ranged between 0.5 and $6 \mathrm{wt} \%$, were catalytically active in the oxidative dehydrogenation (ODH) of propane and ethylbenzene ${ }^{12}$. Because of their mesoporous structure, Mo-MCM-41 materials are being used for the oxidation of relatively large compounds, such as anthracene or 9,10 -anthraquinone ${ }^{13}$. However, less attention was paid to the synthesis, characterization and electrochemical sensing property of Ag/Mo incorporated MCM-41. In this paper, we have reported the preparation of Ag/Mo-MCM-41, using DHT. XRD, FE-SEM and FT-IR have been used to characterize the mesoporous electrocatalyst. The prepared Ag/Mo-MCM-41 has been used to modify the GCE. The modified GCE shows lower anodic peak potential with larger current response for the electrochemical oxidation of 4-CP when compared to the bare GCE.

\section{Experimental}

Sodium metasilicate, silver nitrate, ammonium molybdate, cetyltrimethylammonium bromide (CTAB) and sulphuric acid were purchased from Qualigens and used as received. Deionized water was used throughout the experiment.

\section{Characterization methods}

The synthesized sample was studied by FT-IR spectroscopy using a Schimadzu FT-IR 8300 series instrument. The crystalline structure and crystallite size of the sample was analyzed by a Rich Siefert 3000 diffractometer with $\mathrm{Cu}-\mathrm{K} \alpha_{1}$ radiation $(\lambda=1.5406 \AA)$. In order to have an elemental composition in Ag/Mo-MCM-41 samples, energy dispersive spectroscopy (EDS) was carried out with EDAX Prime equipment coupled to a JEOL 5800 LV Scanning Electron Microscope. The analyses were randomly taken in several sample zones to have a representative value of the elemental composition at low magnification. Morphological characterization was carried out using a HITACHI SU6600 field emission-scanning electron microscopy. FE-SEM specimens were prepared by dispersing the sample in ethanol with ultrasound for 5 minutes. A drop of the suspension was placed into a holey carbon $\mathrm{Cu}$ grid and was allowed to dry. 


\section{Electrochemical experiment}

The modifying process of the electrode was followed by literature method ${ }^{14-15}$ which is as follows: Electrochemical characterization was carried out by cyclic voltammetry $(\mathrm{CV})$ in a conventional three-electrode cell. A GCE with a surface area of $0.07 \mathrm{~cm}^{2}$ was used as working electrode. Mesoporous electrocatalyst suspension was prepared by dispersing $1 \mathrm{mg}$ of $\mathrm{Ag} / \mathrm{Mo}-\mathrm{MCM}-41$ in $5 \mathrm{~mL}$ of acetone. Mesoporous electrocatalyst suspension which contained $5 \mu \mathrm{L}$ was spread on the electrode surface from the ultrasonicated aliquots and dried at room temperature. Electrochemical measurements were performed at $298 \mathrm{~K}$ using a $\mathrm{CHI} 600 \mathrm{~A}$. A three-electrode cell was used with a saturated calomel electrode (SCE: $\mathrm{Ag} / \mathrm{AgCl} / \mathrm{sat} . \mathrm{KCl}$ ) as reference electrode and platinum wire as counter electrode. The CV studies were performed in $0.1 \mathrm{M}$ PBS electrolyte solution saturated with nitrogen at potential range 0 to $+1.0 \mathrm{~V}$ versus SCE and scan rate of $10 \mathrm{mVs}^{-1}$.

\section{Synthesis of Ag/Mo-MCM-41}

The Ag/Mo-MCM-41 mesoporous electrocatalyst with variable $\mathrm{Si} /(\mathrm{Ag} / \mathrm{Mo})$ ratios were synthesized by the following procedure: $18.94 \mathrm{~g}$ of sodium metasilicate was dissolved in deionized water under mechanical stirring. To this solution, the amount of $\mathrm{Ag} / \mathrm{Mo}$ source was slowly added by dissolving in water. The $\mathrm{pH}$ was adjusted to 10.5 with $2 \mathrm{M}$ sulphuric acid and the obtained gel was stirred for $1 \mathrm{~h}$. To this mixture, an aqueous solution of CTAB was added very slowly and the mixture was continuously stirred for another $1 \mathrm{~h}$ at room temperature. The gel was transferred into Teflon-lined stainless steel autoclave and kept at $170{ }^{\circ} \mathrm{C}$ for $12 \mathrm{~h}$. The obtained solid product was cooled to room temperature, filtered, washed with de-ionized water and dried at $100{ }^{\circ} \mathrm{C}$. The sample was then calcined in air at $550{ }^{\circ} \mathrm{C}$ for $6 \mathrm{~h}$. The molar composition of the gel was subjected to hydrothermal synthesis as follows: $\mathrm{SiO}_{2}$ : $1 / \mathrm{X} \mathrm{Ag} / \mathrm{MoO}_{3}$ : 0.2 CTAB: $0.89 \mathrm{H}_{2} \mathrm{SO}_{4}$ : $120 \mathrm{H}_{2} \mathrm{O}$. Here, $\mathrm{n}=0.007-0.04$. The samples are designated as $\mathrm{Ag} / \mathrm{Mo}-\mathrm{MCM}-41(\mathrm{X})$ where $\mathrm{X}$ is the $\mathrm{Si} /(\mathrm{Ag} / \mathrm{Mo})$ ratio in the gel: 25, 50, 100 and 150 .

\section{Result and Discussion}

\section{$X$-Ray diffraction analysis}

The mesostructural and ordered characteristics of the samples were determined by low angle XRD analysis. The low-angle XRD pattern of $10 \mathrm{wt} \% \mathrm{Ag} / \mathrm{Mo}-\mathrm{MCM}-41$ with different weight ratios of $\mathrm{Si} / \mathrm{Mo}(150,100,50$ and 25) are shown in the Figure 1. The diffraction peak corresponding to (100) plane of the mesostructured MCM-41 (indicates the ordered pore structure of MCM-41) are absent. It suggests that the hexagonal pore structure of MCM-41 is distorted after being loaded with $\mathrm{Ag}$ nanoparticles. Figure 2 shows the formation of cubic phase metallic Ag nanoparticles (JCPDS No. 85-0597) inside the channels, which leads to the loss of ordered structure. In addition, the diffraction peaks were broadened and slightly shifted to lower angle with increasing $\mathrm{Ag}$ content. It explains that the silver nanoparticles are filled in the pores of MCM-41, which deform the matrix ${ }^{14}$. It is observed that in all the samples no phases corresponding to $\mathrm{MoO}_{3}$ or molybdate species were present. Absence of $\mathrm{MoO}_{3}$ or molybdate species even in the impregnated samples is probably due to the presence of $\mathrm{X}$-ray insensitive amorphous phase. Kovacheva et al. ${ }^{15}$ have reported the absence of such species on Moimpregnated HY zeolite. 


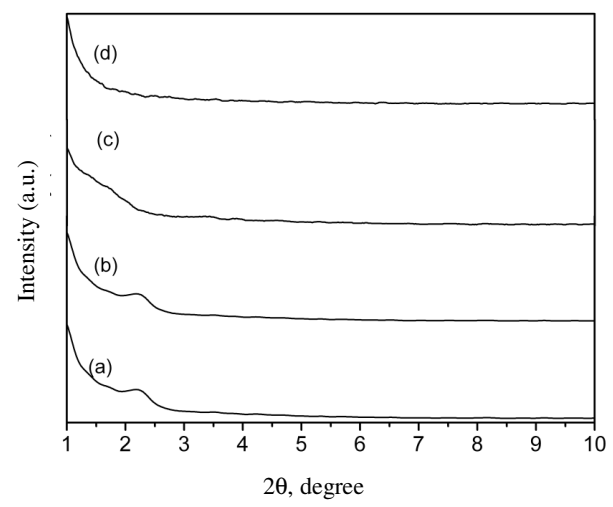

Figure 1. Low-angle XRD pattern of Ag/Mo-MCM-41 with different $\mathrm{Si} / \mathrm{Mo}$ ratio (a) $\mathrm{Si} / \mathrm{Mo}=150$; (b) $\mathrm{Si} / \mathrm{Mo}=100$; (c) $\mathrm{Si} / \mathrm{Mo}=50$ and (d) $\mathrm{Si} / \mathrm{Mo}=25$

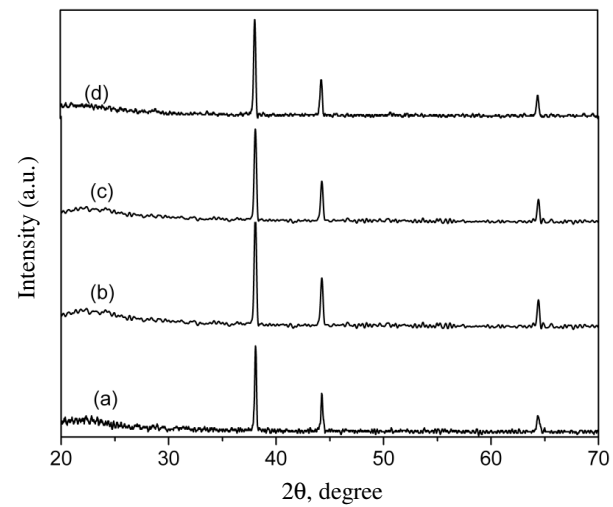

Figure 2. High-angle XRD pattern of $\mathrm{Ag} / \mathrm{Mo}-\mathrm{MCM}-41$ with different $\mathrm{Si} / \mathrm{Mo}$ ratio (a) $\mathrm{Si} / \mathrm{Mo}=150$; (b) $\mathrm{Si} / \mathrm{Mo}=100$; (c) $\mathrm{Si} / \mathrm{Mo}$ $=50$ and $(\mathrm{d}) \mathrm{Si} / \mathrm{Mo}=25$

\section{FT-IR analysis}

The FT-IR spectra of Ag/Mo-MCM-41 samples with different Si/Mo ratio (150, 100, 50 and 25) are given in Figure 3. Figure 3a shows the absorption bands at 1631, 1105, 965, 809 and $483 \mathrm{~cm}^{-1}$. The strong band at $1631 \mathrm{~cm}^{-1}$ ascribed to bending vibration of $\mathrm{O}-\mathrm{H}$ in water molecule. It shows that a large number of $-\mathrm{OH}$ groups exist on the surface of MCM-41, which play a vital role for bonding metal ions from the impregnating sol. The band observed at 1105, 809 and $483 \mathrm{~cm}^{-1}$ are due to symmetric stretching, asymmetric stretching and bending vibration of $\mathrm{Si}-\mathrm{O}-\mathrm{Si}$. In addition, these bands are narrow and more intense due to free vibration of $\mathrm{Si}-\mathrm{O}-\mathrm{Si}$ bonds in $\mathrm{Ag} @$ Mo-MCM-41. The peak at $965 \mathrm{~cm}^{-1}$ is attributed to the vibration of oxygen atom shared by framework $\mathrm{Si}$ and Mo atoms ${ }^{16}$. It can be seen that, the intensity of the $\mathrm{Si}-\mathrm{O}-\mathrm{Mo}$ peak at $965 \mathrm{~cm}^{-1}$ increases with increasing molybdenum content (Figure 4), which is in good agreement with the $\mathrm{XRD}$ results. This is the evidence of molybdenum incorporating into the silica framework.

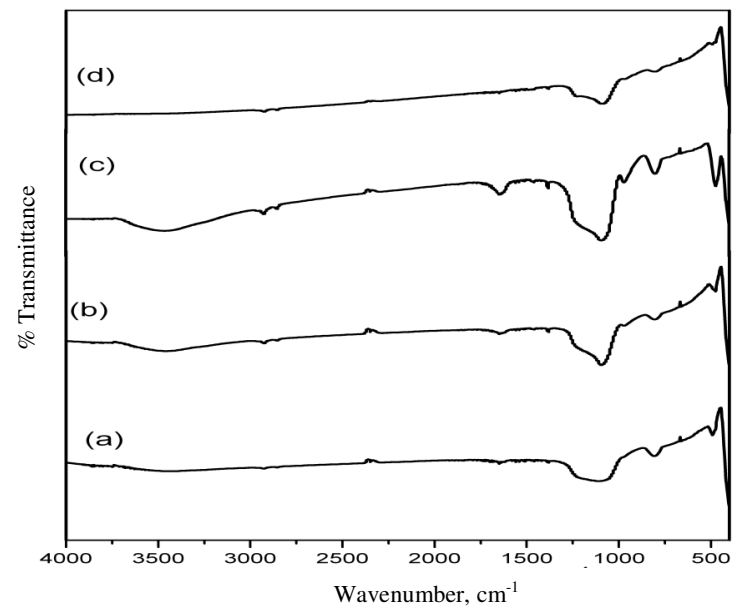

Figure 3. FT-IR spectra of Ag/Mo-MCM-41 with different Si/Mo ratio (a) Si/Mo $=150$; (b) $\mathrm{Si} / \mathrm{Mo}=100 ;$ (c) $\mathrm{Si} / \mathrm{Mo}=50$ and (d) $\mathrm{Si} / \mathrm{Mo}=25$ 
The FT-IR spectra of less Mo-containing MCM-41 samples do not show obvious $\mathrm{MoO}_{3}$ absorption bands, and only $\mathrm{SiO}_{2}$ absorption bands (Figure $4 \mathrm{a}-\mathrm{c}$ ) are observed. The band at $475 \mathrm{~cm}^{-1}$ is attributed to $\mathrm{MoO}_{3}$ absorption band (Figure 4d). This phenomenon also indicates the incorporation of Mo into MCM-41 frameworks or its dispersion on MCM-41surface.

\section{Morphological analysis}

Figure 5 shows the SEM images of Ag@Mo-MCM-41 with Si/Mo ratio is 25. The SEM images indicated that the particles are agglomerated with irregular morphological particles whose size is in the $\mu \mathrm{m}$ range. In addition that the Ag nanoparticles incorporated samples were clearly seen from the SEM images. Further, the morphology of the higher molybdenum contained Ag/Mo-MCM-41 is similar to that of lower molybdenum incorporated MCM-41 and hence the synthesized mesoporous samples were structurally unchanged upon the increase in molybdenum incorporation. Figure 5 clearly shows that the sample are agglomerated by sponge-like particles with bright Ag nanospheres.

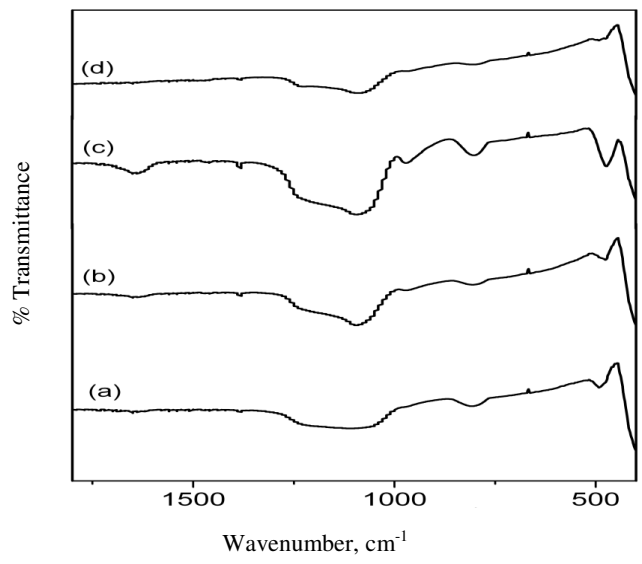

Figure 4. FT-IR spectra (expanded view) of $\mathrm{Ag} / \mathrm{Mo}-\mathrm{MCM}-41$ with different $\mathrm{Si} / \mathrm{Mo}$ ratio (a) $\mathrm{Si} / \mathrm{Mo}=150$ (b) Si/Mo $=100$ (c) $\mathrm{Si} / \mathrm{Mo}=50$ and (d) $\mathrm{Si} / \mathrm{Mo}=25$

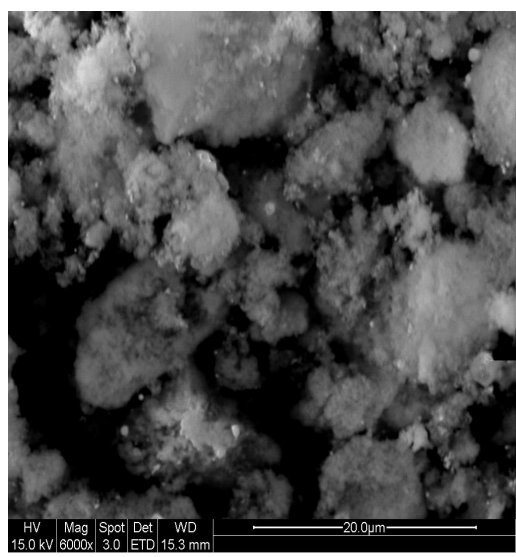

Figure 5. SEM image of Ag@MoMCM-41

\section{Electrochemical sensing property of Ag/Mo-MCM-41}

Cyclic voltammograms (CVs) were used to determine the electrocatalytic behaviors of the $\mathrm{Ag} / \mathrm{Mo}-\mathrm{MCM}-41 / \mathrm{GCE}$ towards the oxidation of 4-CP. Figure 6 shows the CV's of bare and $\mathrm{Ag} / \mathrm{Mo}-\mathrm{MCM}-41 / \mathrm{GCE}$ in the presence of $0.1 \mathrm{mM} 4-\mathrm{CP}$ in $0.1 \mathrm{M}$ PBS at a scan rate of 0.01 $V / s$. The CV of 4-CP at bare GCE (Figure 6a) shows a very broad peak at about $+0.68 \mathrm{~V}$. The 4-CP voltammogram obtained for MCM-41/GCE showed a broad oxidation peak at $+0.67 \mathrm{~V}$. However the 4-CP voltammogram obtained for Ag/Mo-MCM-41/GCE showed well defined oxidation wave with shift in oxidation potential and increase of the oxidation peak current than the bare and pure MCM-41/GCE, indicating the electrocatalytic ability of the Ag/Mo-MCM-41/GCE. This electrocatalytic effect was attributed to the larger available surface area of the modifying layer. From the Figure 6, it can be seen that the oxidation potential and current response of 4-CP varied with the amount of the incorporated molybdenum. For better clarification, we have plotted the function of Si/Mo ratio with respect to oxidation peak potential and anodic peak current (Figure 7). 
Especially, Ag/Mo-MCM-41(25)/GCE showed lowest oxidation potential at $+0.45 \mathrm{~V}$. The over potential had thus decreased by $+0.23 \mathrm{~V}$ indicating the strong electrocatalytic effect of Ag/Mo-MCM-41(25)/GCE modified layer. The results indicate that catalytic reaction occurred between the Ag/Mo-MCM-41(25)/GCE with 4-CP.

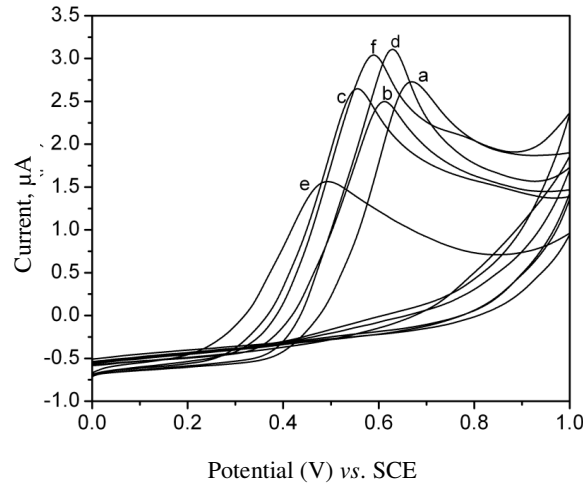

Figure 6. Cyclic voltammetric response of $0.1 \mathrm{mM} 4-\mathrm{CP}$ at (a) bare, (b) Pure MCM41/GCE (c) Ag@ Si/Mo = 150/GCE (d) Ag@ $\mathrm{Si} / \mathrm{Mo}=100 / \mathrm{GCE}$ (e) Ag@Si/Mo =50/GCE and (f) Ag@ Si/Mo= 25/GCE

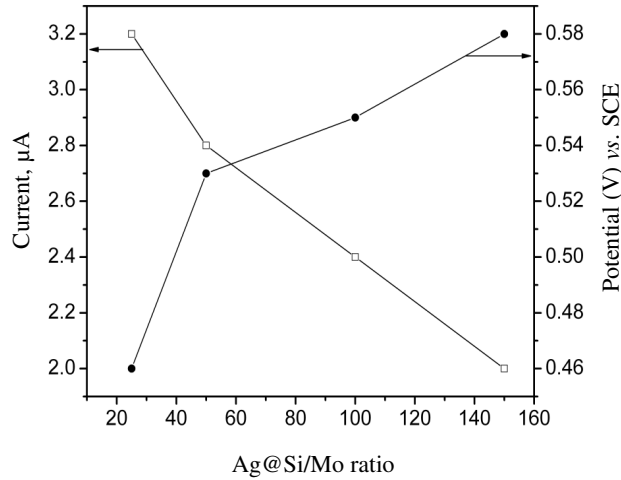

Figure 7. Plots of concentration of Mo vs. peak potential and current response

The catalytic reaction facilitates electron transfer between 4-CP and the modified electrode $^{13}$, as a result the electrochemical oxidation of 4-CP becomes easier. The reason for this is that the $\mathrm{Ag} / \mathrm{Mo}-\mathrm{MCM}-41(25)$ can act as a promoter to increase the rate of electron transfer, lower the overpotential of 4-CP at the bare electrode and the anodic peak shifts less positive potential.

\section{Conclusion}

Ag/Mo-MCM-41 was synthesized by simple direct hydrothermal method. The synthesized Ag/Mo-MCM-41 was characterized by XRD, FTIR and FE-SEM. XRD reveals the formation of $\mathrm{Ag} / \mathrm{Mo}-\mathrm{MCM}-41$. FTIR shows the incorporation of molybdenum into the $\mathrm{Si}$ frame work. FE-SEM analysis indicates that the sample was found to be aggregated in sponge like nature with bright particle which indicative of $\mathrm{Ag}$ particle. Electrochemical experiments showed that Ag/Mo-MCM-41(25)/GCE had an excellent electrochemical sensing property towards the oxidation of 4-CP.

\section{References}

1. Kresge C T, Leonowicz M E, Roth W J, Vartuli J C and Beck J S, Nature, 1992, 359(6397), 710-712.

2. Aguado J, Serrano D P, Romero M D and Escola J M, Chem Commun., 1996, 765.

3. Corma A, Chem. Rev., 1997, 97, 2373.

4. Corma A, Navarro M T and Pariente J P, Chem Commun., 1994, 147.

5. Reddy K M, Moudrakovski I and Sayari A, Chem Commun., 1994, 1059.

6. Wang Y, Ohishi Y, Shishido T, Zhang Q, Yang W, Guo Q, Wan H and Takehira K J, Catal., 2003, 220, 347-357.

7. Srinivas N, Radha Rani V, Kulkarni S J and Raghavan K V, J Mol Catal A, 2002, 179, 221-231. 
8. Giribabu K, Suresh R, Narayanan V, Vijayalakshmi L and Stephen A, IEEE Conference Publication, 2011, 485-487.

9. Suresh R, Prabu R, Vijayaraj A, Giribabu K, Stephen A and Narayanan V, Synth React Inorg Metal-Org nano-Met Chem., 2012, 42, 303-307.

10. Selvaraj M, Kim B H and Lee T G, Chem. Lett., 2005, 34, 1290-1291.

11. Cherian M, Rao M S and Yang W T, Appl Catal A, 2002, 21, 233.

12. Shankar H, Rajasudha G, Karthikeyan A, Narayanan V and Stephen A, Nanotechnology, 2008, 19, 315711-375717.

13. Suresh R, Prabu R, Vijayaraj A, Giribabu K, Stephen A and Narayanan V, Mater Chem Phys., 2012, 134, 590-596.

14. Cid R, Gil Llambias F J, Gonzalez M and Lopez Agudo A, Catal Lett., 1994, 24, 147-157.

15. Kovacheva P, Arishtirova K and Davidova N, Appl Catal A, 1997, 163, 255.

16. Hongfei Fan, Xin Jin, Lei Wang, Christopher T. Williams, Tianxi Cai and Changhai Liang, Catal Lett., 2012, 142(7), 854-859. 